\title{
Spatial-Temporal Variability and Dust-Capture Capability of 8 Plants in Urban China
}

\author{
Yan Zha', Yiyun Shi ${ }^{1}$, Jie Tang ${ }^{2}$, Xin Liu ${ }^{2}$, Chi Feng ${ }^{1}$, Yinlong Zhang ${ }^{1 *}$ \\ ${ }^{1}$ Co-Innovation Center for Sustainable Forestry in Southern China, Jiangsu Province Key Laboratory of Ecological \\ Engineering, Nanjing Forestry University, Nanjing, China \\ ${ }^{2}$ School of Resources and Environment, Anhui Agricultural University, Anhui, China \\ ${ }^{3}$ Co-Innovation Center for Sustainable Forestry in Southern China, Jiangsu Province Key Laboratory of Soil \\ and Water Conservation and Ecological Restoration, Nanjing Forestry University, Nanjing, China
}

Received: 6 December 2017

Accepted: 2 January 2018

\begin{abstract}
Urban plants have been proven to mitigate ambient particulate matter (PM), which can benefit urban planners in their attempts to control urban air pollution. In this study, PM depositions on the leaves of 8 tree species were quantitatively analysed in 7 functional areas of the city of Nanjing, China, over the course of one year. The results demonstrated that leaf PM included different particle size fractions $\left(\mathrm{PM}_{10}\right.$ and $\left.\mathrm{PM}_{2.5}\right)$, and differed among seasons and species. The highest amounts of total PM, $\mathrm{PM}_{10}$, and $\mathrm{PM}_{2.5}$ were found in the industrial area, and the mean values were $80.24 \mu \mathrm{g} / \mathrm{cm}^{2}, 52.14 \mu \mathrm{g} / \mathrm{cm}^{2}$, and $15.51 \mu \mathrm{g} / \mathrm{cm}^{2}$, respectively, and the highest accumulation of total PM $\left(60.65 \mu \mathrm{g} / \mathrm{cm}^{2}\right), \mathrm{PM}_{10}\left(37.29 \mu \mathrm{g} / \mathrm{cm}^{2}\right)$, and $\mathrm{PM}_{2.5}\left(11.23 \mu \mathrm{g} / \mathrm{cm}^{2}\right)$ occurred in winter. Significant differences were found between the tree species tested. Cedrus deodara exhibited high amounts of the total $\mathrm{PM}, \mathrm{PM}_{10}$, and $\mathrm{PM}_{2.5}$ accumulations. This study examined the mass and quantity distribution of PM among tree species, and identified the particles combined with a scanning electron microscope (SEM). In terms of particle mass, $48 \%$ of the identified particles had a diameter of 10 $\mu \mathrm{m}$, and only $18.3 \%$ of them had a diameter of $2.5 \mu \mathrm{m}$. In terms of particle number, the results indicated that $73 \%$ of them had a diameter of $2.5 \mu \mathrm{m}$, and only $5.5 \%$ of them had a diameter of $10 \mu \mathrm{m}$. To test the relationship between leaf traits and $\mathrm{PM}_{2.5}$ accumulation, results showed that stomata size, density, and hair were significantly related to the $\mathrm{PM}_{2.5}$ capture quantity. As far as we know, this is the first paper to present the mass and quantity distribution of the PM of different tree species in Nanjing. The results not only give comprehensive insights into the dust-retaining capability of tree species but also offer a selection of species for urban green areas where the goal is to mitigate urban airborne PM.
\end{abstract}

Keywords: air pollution, particulate matter, spatial and temporal, urban tree species

*e-mail: ecoenvylz@163.com 


\section{Introduction}

It is well known that rapid urbanisation has resulted in the emission of air pollutants, which have placed a heavy burden on the local environment and human health. Dust pollution in the atmosphere, particularly that of pollutant particles below $10 \mu \mathrm{m}\left(\mathrm{PM}_{10}\right)$, poses adverse health effects associated with their inhalation [1-3], and $\mathrm{PM}_{2.5}$ is closely associated with the occurrence of respiratory and cardio-vascular diseases, which can reach the lungs and alveolar regions [4]. Additionally, particulate matter (PM) pollution has dramatically increased during the past 10 years [3, 5], especially in China's urban areas [6]. Worsening air quality of urban sites has become an issue of increasing concern due to its adverse effects on climate change and public health [7]. Although serious effective measures have been taken to mitigate atmospheric pollution, fog-haze episodes frequently appear in China, including in Nanjing. Therefore, to investigate the spatialtemporal variation of PM is essential to understanding the current air pollution status in China.

Several studies have indicated that urban vegetation has a positive influence on air purity and can significantly affect air quality [8-10]. Previous works qualitatively evaluated the ability of different species to accumulate and retain PM [11-13]. The surface roughness, hairs, morphology, and the wax of leaves can all affect the adsorption of PM [12]. Many attempts have indicated that broadleaf species with rough leaf surfaces are more efficient in capturing PM than those with smooth leaf surfaces [14-15]. Conifers have species-specific features such as leaf morphology, leaf type, and leaf area index that act as the main structures and are considered more effective at capturing PM [16]. Other studies have investigated PM deposition on vegetation in wind tunnels to investigate the deposition velocity on different tree species [18-19]. In conclusion, previous studies on particles captured by plants have mostly focused on particle mass and size distribution [20-23] to evaluate capture capacities of species. Few studies have examined the particle density per unit [24-25] Song et al. (2015), Ottele et al. (2000) [21], and Hofman et al. (2013) indicate that the biomagnetic monitoring of tree leaves has proven to be a good estimator for ambient particulate concentrations [26]. However, the spatial-temporal contamination levels of PM of leaf surfaces in Nanjing are is still not understood.

In this study, we quantified the mass, size, number characteristic, and the relationship between leaf morphology characteristics (such as villus and stomata) and $\mathrm{PM}_{2.5}$ captured by plants based on scanning electron microscope (SEM) micrographs. The present study used the city of Nanjing in China as a case study, as this is one of the most polluted cities in China, especially for PM pollution. We aimed to: (1) quantify deposited particles to assess the spatial-temporal PM distribution, (2) compare the mass and quantity distribution with 8 tree species, (3) compare the particle retention efficiency of 8 tree species of different vegetation types, and (4) explore the relationship between $\mathrm{PM}_{2.5}$ capability and morphology of the leaf surface.

\section{Materials and Methods}

\section{Study Area}

Nanjing is one of the biggest cities and a major political, economic, and industrial centre in southern China, with an area of $6,587 \mathrm{~m}^{2}$ and a population of more

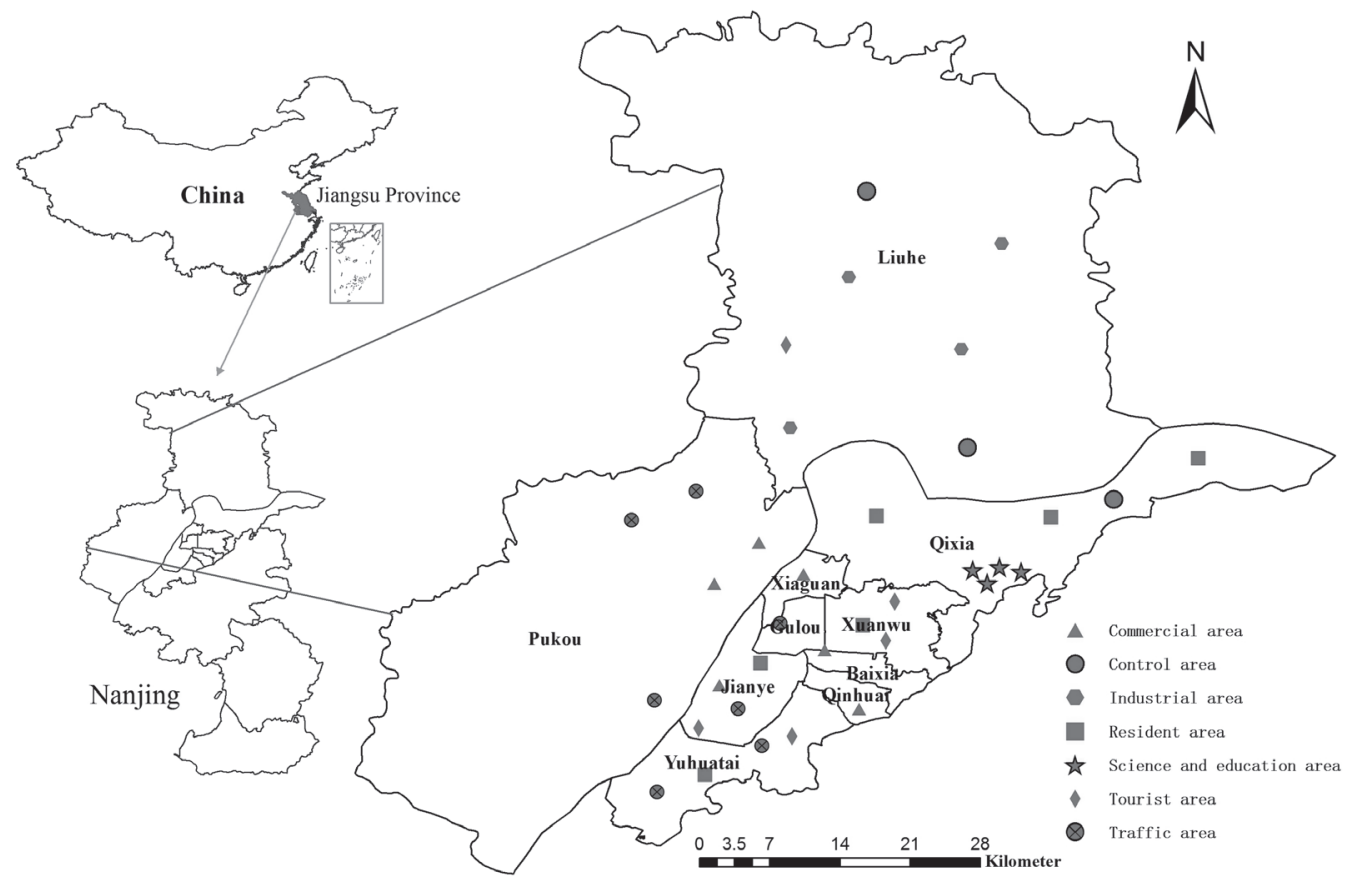

Fig. 1. Locations of sampling sites in urban Nanjing. 
than 8.27 million. Since the 21st century, the region has experienced serious rapid urbanization accompanied by deterioration of the atmospheric environment. The sampling sites were divided according to land-use type. Seven types of urban area have been identified as being characteristic of urban Nanjing, namely, industrial areas (IA), residential areas (RA), commercial areas (CA), traffic areas (TA), science and education areas (SER), tourist areas (TR), and control areas (CAR). In each of these urban area types, the locations of which are shown in Fig. 1, trees were sampled.

\section{Species Sampled}

Eight tree species that are widely distributed in Nanjing (Cedrus deodara, Pinus tabuliformis, Sabina chinensis, Osmanthus fragrans, Cinnamomum camphora, Photinia fraseri, and Pittosporum tobira) were selected for this study. Samples were collected in December 2016 and March, June, and October 2017. There were at least 28 days with no precipitation before sampling. Liu et al. (2013) indicated that leaves attained the maximum dust-retaining capabilities [19]. Sampling dates were selected during times of no precipitation and wind. Each tree species was in good condition, with no disease and/or pests. For each tree, mature and healthy leaves were collected using a pruner from $\mathrm{N}, \mathrm{W}, \mathrm{S}$, and $\mathrm{E}$ facing aspects at a height of 1-3 $\mathrm{m}$ above the ground. Six individuals were sampled for each species. All leaf samples were collected from a single individual and stored at $44^{\circ} \mathrm{C}$ in a clean laboratory refrigerator prior to analysis. PM collected from leaf surfaces was analysed using the methods of Dzierżanowski et al. (2011) [27].

\section{Quantitative Analysis of PM}

The filters used for the analysis were first dried for 30 minutes at $60^{\circ} \mathrm{C}$ in a drying chamber (YB881-4, Suzhou, China). A balance and a humidity controller (WHD48-11, ACRELCo., Ltd., Jiangsu, China) were placed in the balancing box. To avoid electrostatic charges on the filters, they were first placed in a polytetrafluoroethylene (PTFE) balancing box under constant temperature $\left(25^{\circ} \mathrm{C}\right)$ and constant humidity $(40 \%)$ for 48 hours. Every leaf sample was placed in a glass container with $250 \mathrm{~mL}$ of water and agitated for 60 seconds in order to wash off particles from the leaf surface. The three fractions of particulate matter were collected on filters: (1) large: $>10 \mu \mathrm{m}$, (2) coarse: 2.5 10 $\mu \mathrm{m}$, and (3) fine: $0.2 \sim 2.5 \mu \mathrm{m}$. Samples were stored in paper bags in a dryer (DHG-9030A, Shanghai Jinghong Scientific Instrument Co., Ltd., Shanghai, China) at $60^{\circ} \mathrm{C}$ for 48 hours. Filters were weighed before and after particulate removal and stored using a balance (Sartorius Beijing Scientific Instrument Co., Ltd., Beijing, China) sensitive to $0.00001 \mathrm{~g}$ to calculate the mass of PM in each fraction of every sample.

\section{Scanning Electron Microscopy of the Leaves}

A scanning electron microscope (SEM, FEI Quanta-200, USA) was used to statistically quantity the different sizes of PM and test the relationship between leaf traits and $\mathrm{PM}_{2.5}$ accumulation. The method used was as follows: small strips (approximately $1 \mathrm{~cm}^{2}$ ) were trimmed from areas between the margin and midrib of leaves, and then they were dried with a vacuum freeze drier (Labconco, Kansas City, MO, USA) for 5 days at $-83^{\circ} \mathrm{C}$ to a constant weight. The prepared samples were attached to the SEM stub with double-sided adhesive tape. The samples were gold-coated to enhance electrical conductivity before analysis. Photographs were taken of randomly chosen spots at $1,000 \times$ and $2,000 \times$ magnification at $5 \mathrm{kV}$. Particle counting was performed using ImageJ software (National Institutes of Health, USA), according to the method described by Ottelé et al. (2010) [25], and the amount and size of stomata, groove width, and villus density were expressed per leaf surface area as measured by ImageJ software.

\section{Data Analysis}

One-way analysis of variance (ANOVA) was used to test for differences in PM accumulation in different seasons and among species. Multiple comparisons among species were performed using least-significant difference multiple comparison tests. Values presented on the bar charts are mean $\pm \mathrm{SE}, \mathrm{n}=4$. The figures were calculated using Origin 9.0 (Microcal, Northampton, MA, USA). The particle number identified on a leaf per square centimetre (PNC) was calculated by dividing the number of particles classified by the object-based approach by the area of the SEM micrograph.

\section{Results and Discussion}

\section{Seasonal Variation Characteristics of Different Sizes of PM on Leaf Surfaces}

Following the classifications, we assessed the leaf particle accumulation at the seasonal level (Fig. 2). The seasonal variation in the amounts of different sizes of PM were obviously higher in winter than the other three seasons $(P<0.01)$. The maxima of total $\mathrm{PM}, \mathrm{PM}_{10}$, and $\mathrm{PM}_{25}$ levels were found in winter, with the mean values of $60.65 \mu \mathrm{g} / \mathrm{cm}^{2}, 37.29 \mu \mathrm{g} / \mathrm{cm}^{2}$, and $11.23 \mu \mathrm{g} / \mathrm{cm}^{2}$, respectively. The difference in the amount of PM between autumn and spring was determined by independent samples t-test. The probabilities ( $p$-value of two-tailed significance) for the amounts of different sizes of PM were $>0.05$, indicating that the amounts of PM on the leaf surfaces were not much different in autumn and spring. The seasonal variation characteristics of the amounts of $\mathrm{PM}_{10}$ and $\mathrm{PM}_{2.5}$ were similar to the total $\mathrm{PM}$, which decreased in the following order: winter $>$ autumn $>$ spring $>$ summer. 


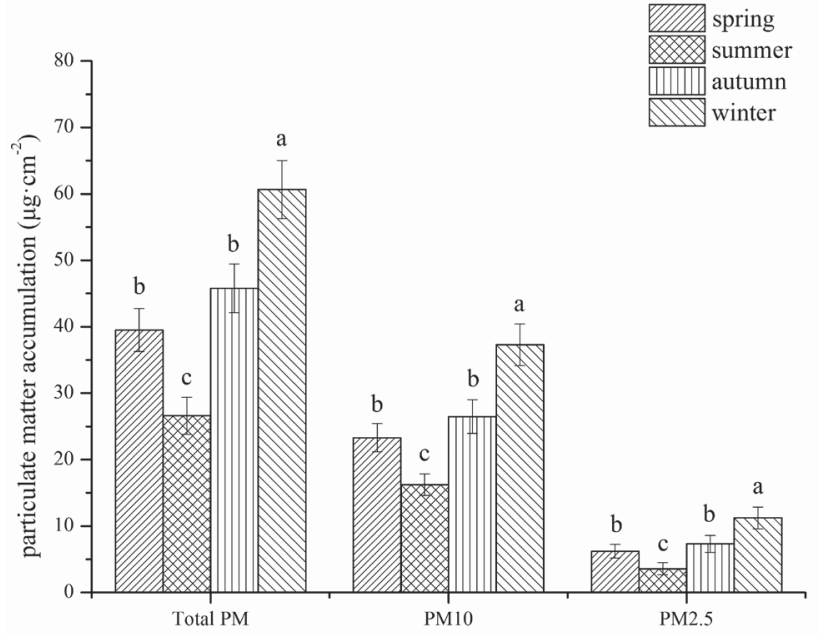

Fig. 2. Total PM, PM10 and $\mathrm{PM}_{2.5}$ accumulation on leaf surfaces in different seasons.

\section{Spatial Variation Characteristics of PM on Leaf Surfaces}

The average amounts of total $\mathrm{PM}, \mathrm{PM}_{10}$, and $\mathrm{PM}_{2.5}$ retained on leaf surfaces from different functional areas in Nanjing are shown in Tables 1, 2, and 3. Based on the amounts of $\mathrm{PM}, \mathrm{PM}_{10}$, and $\mathrm{PM}_{2.5}$ on leaf surfaces in each functional area, they could be classified as follows: IA $>$ CA $>$ TA $>$ RA $>$ SER $>$ TAR $>$ CAR. The highest values of $\mathrm{PM}, \mathrm{PM}_{10}$, and $\mathrm{PM}_{25}$ were observed in IA, which greatly exceed that held on leaf surfaces in the other functional area $(P<0.05)$ and is attributed to the incomplete combustion of petroleum and coal release from industrial areas that might enhance the amount of PM. The highest amount of PM in IA observations was in line with the previous studies in Huizhou, Guangdong [28], and Guangzhou [29]. In addition, CA and TA could release different sizes of PM from vehicle emissions, which were then deposited on the leaf surfaces and led to more PM. Song et al. (2015) indicated that carbon particle aggregates larger than $10 \mu \mathrm{m}$, also called soot, were aggregates of fine or ultrafine particles that originated from vehicle exhaust and the burning of coal and biomass [24]. Furthermore, spatial contrasts in PM accumulation in CA and TA were associated with plant species growing low to the ground that were presumably more exposed to soil splash on the leaves than trees with an upright growth habit [30]. Dzierżanowski et al. (2011) also observed the largest amount of PM on low-growing shrubs (Spiraea) compared to trees [27]. Meanwhile, RA and SEA had lower traffic and other anthropogenic activities and was far from the city centre, where the low density of residents and traffic led to low pressure

Table 1. Total PM accumulation on leaf surfaces in different seasons.

\begin{tabular}{|c|c|c|c|c|}
\hline \multirow{2}{*}{ Sample } & Spring & Summer & Autumn & Winter \\
\cline { 2 - 5 } & $\left(\mu \mathrm{g} / \mathrm{cm}^{2}\right)$ & $\left(\mu \mathrm{g} / \mathrm{cm}^{2}\right)$ & $\left(\mu \mathrm{g} / \mathrm{cm}^{2}\right)$ & $\left(\mu \mathrm{g} / \mathrm{cm}^{2}\right)$ \\
\hline Industrial area & $57.68 \pm 3.07 \mathrm{a}$ & $39.36 \pm 2.55 \mathrm{a}$ & $68.13 \pm 2.69 \mathrm{a}$ & $80.24 \pm 3.21 \mathrm{a}$ \\
\hline Commercial area & $45.82 \pm 2.40 \mathrm{~b}$ & $29.04 \pm 2.48 \mathrm{~b}$ & $57.60 \pm 2.51 \mathrm{~b}$ & $71.13 \pm 2.65 \mathrm{~b}$ \\
\hline Traffic area & $43.20 \pm 2.61 \mathrm{~b}$ & $26.39 \pm 1.50 \mathrm{~b}$ & $51.09 \pm 1.30 \mathrm{c}$ & $67.02 \pm 2.63 \mathrm{c}$ \\
\hline Residential area & $34.17 \pm 2.19 \mathrm{c}$ & $20.59 \pm 2.37 \mathrm{c}$ & $42.53 \pm 1.08 \mathrm{~d}$ & $56.86 \pm 1.60 \mathrm{~d}$ \\
\hline Science and education area & $31.94 \pm 1.46 \mathrm{c}$ & $17.66 \pm 1.62 \mathrm{~cd}$ & $39.06 \pm 0.94 \mathrm{e}$ & $50.16 \pm 1.05 \mathrm{e}$ \\
\hline Tourist area & $27.53 \pm 1.73 \mathrm{~d}$ & $15.02 \pm 1.55 \mathrm{~d}$ & $33.22 \pm 1.67 \mathrm{f}$ & $46.52 \pm 0.75 \mathrm{f}$ \\
\hline Control area & $21.29 \pm 1.15 \mathrm{e}$ & $13.83 \pm 1.45 \mathrm{~d}$ & $23.44 \pm 1.09 \mathrm{~g}$ & $41.05 \pm 1.17 \mathrm{~g}$ \\
\hline
\end{tabular}

Table 2. $\mathrm{PM}_{10}$ accumulation on leaf surfaces in different seasons.

\begin{tabular}{|c|c|c|c|c|}
\hline \multirow{2}{*}{ Sample } & Spring & Summer & Autumn & Winter \\
\cline { 2 - 5 } & $\left(\mu \mathrm{g} / \mathrm{cm}^{2}\right)$ & $\left(\mu \mathrm{g} / \mathrm{cm}^{2}\right)$ & $\left(\mu \mathrm{g} / \mathrm{cm}^{2}\right)$ & $\left(\mu \mathrm{g} / \mathrm{cm}^{2}\right)$ \\
\hline Industrial area & $33.62 \pm 1.63 \mathrm{a}$ & $25.16 \pm 1.09 \mathrm{a}$ & $38.88 \pm 1.03 \mathrm{a}$ & $52.14 \pm 1.68 \mathrm{a}$ \\
\hline Commercial area & $27.07 \pm 2.08 \mathrm{~b}$ & $18.12 \pm 1.65 \mathrm{~b}$ & $31.59 \pm 2.01 \mathrm{~b}$ & $45.09 \pm 2.08 \mathrm{~b}$ \\
\hline Traffic area & $24.59 \pm 1.21 \mathrm{~b}$ & $16.48 \pm 0.73 \mathrm{~b}$ & $28.73 \pm 1.73 \mathrm{c}$ & $40.89 \pm 1.49 \mathrm{c}$ \\
\hline Residential area & $19.74 \pm 2.15 \mathrm{c}$ & $11.37 \pm 0.95 \mathrm{c}$ & $22.63 \pm 1.88 \mathrm{~d}$ & $35.70 \pm 1.02 \mathrm{~d}$ \\
\hline Science and education area & $17.64 \pm 1.01 \mathrm{~cd}$ & $10.18 \pm 1.08 \mathrm{~cd}$ & $20.09 \pm 0.94 \mathrm{e}$ & $31.50 \pm 0.94 \mathrm{e}$ \\
\hline Tourist area & $15.13 \pm 0.86 \mathrm{~d}$ & $8.75 \pm 0.77 \mathrm{~d}$ & $17.59 \pm 1.08 \mathrm{f}$ & $27.69 \pm 1.38 \mathrm{f}$ \\
\hline Control area & $12.78 \pm 1.37 \mathrm{~d}$ & $7.30 \pm 0.62 \mathrm{~d}$ & $14.07 \pm 0.63 \mathrm{~g}$ & $22.43 \pm 0.99 \mathrm{~g}$ \\
\hline
\end{tabular}


Table 3. $\mathrm{PM}_{2.5}$ accumulation on leaf surfaces in different seasons.

\begin{tabular}{|c|c|c|c|c|}
\hline \multirow{2}{*}{ Sample } & Spring & Summer & Autumn & Winter \\
\cline { 2 - 5 } & $\left(\mu \mathrm{g} / \mathrm{cm}^{2}\right)$ & $\left(\mu \mathrm{g} / \mathrm{cm}^{2}\right)$ & $\left(\mu \mathrm{g} / \mathrm{cm}^{2}\right)$ & $\left(\mu \mathrm{g} / \mathrm{cm}^{2}\right)$ \\
\hline Industrial area & $9.36 \pm 0.67 \mathrm{a}$ & $5.23 \pm 0.21 \mathrm{a}$ & $10.62 \pm 0.63 \mathrm{a}$ & $15.51 \pm 0.36 \mathrm{a}$ \\
\hline Commercial area & $7.97 \pm 0.43 \mathrm{~b}$ & $4.59 \pm 0.42 \mathrm{~b}$ & $8.93 \pm 0.72 \mathrm{~b}$ & $13.17 \pm 0.62 \mathrm{~b}$ \\
\hline Traffic area & $6.86 \pm 0.57 \mathrm{c}$ & $3.84 \pm 0.11 \mathrm{c}$ & $7.63 \pm 0.73 \mathrm{c}$ & $11.96 \pm 0.82 \mathrm{c}$ \\
\hline Residential area & $5.03 \pm 0.69 \mathrm{~d}$ & $2.97 \pm 0.03 \mathrm{~d}$ & $6.18 \pm 0.15 \mathrm{~d}$ & $9.63 \pm 0.41 \mathrm{c}$ \\
\hline Science and education area & $4.52 \pm 0.12 \mathrm{de}$ & $2.65 \pm 0.55 \mathrm{de}$ & $5.53 \pm 0.52 \mathrm{de}$ & $8.83 \pm 0.53 \mathrm{~d}$ \\
\hline Tourist area & $3.98 \pm 0.66 \mathrm{e}$ & $2.34 \pm 0.36 \mathrm{e}$ & $4.95 \pm 0.77 \mathrm{e}$ & $7.59 \pm 0.24 \mathrm{e}$ \\
\hline Control area & $3.07 \pm 0.28 \mathrm{e}$ & $1.93 \pm 0.17 \mathrm{e}$ & $4.03 \pm 0.26 \mathrm{e}$ & $6.94 \pm 0.73 \mathrm{e}$ \\
\hline
\end{tabular}

in these areas. Przybysz et al. (2014) indicated that the accumulation of total PM showed a big difference between traffic and rural areas [31]. It was well documented that the urban area is an assembly of different land use types with typical and diffuse pollution sources (industry, traffic, and domestic). The distinctive artificial activities in each functional area could release different sizes of $\mathrm{PM}$, which is then deposited on the leaf surface and leads to the amounts of different sizes of PM widely varying between functional areas.

\section{The Mass Distribution of PM Accumulation Among Species}

The results documented the differences in PM accumulation among species (Fig. 3), and showed that $\mathrm{Dp}>10 \mu \mathrm{m}$ comprised more than $25 \%$ of the total PM (by wt) deposited on leaf surfaces among the studied tree species. Fine particles made a small contribution to the total PM (by wt), with a mean average of $12.3-23.4 \%$. The $\mathrm{PM}_{10}$ mass of 8 species contributed $48 \%$ to the total PM mass, with an average of $66.9 \%$, which made the largest

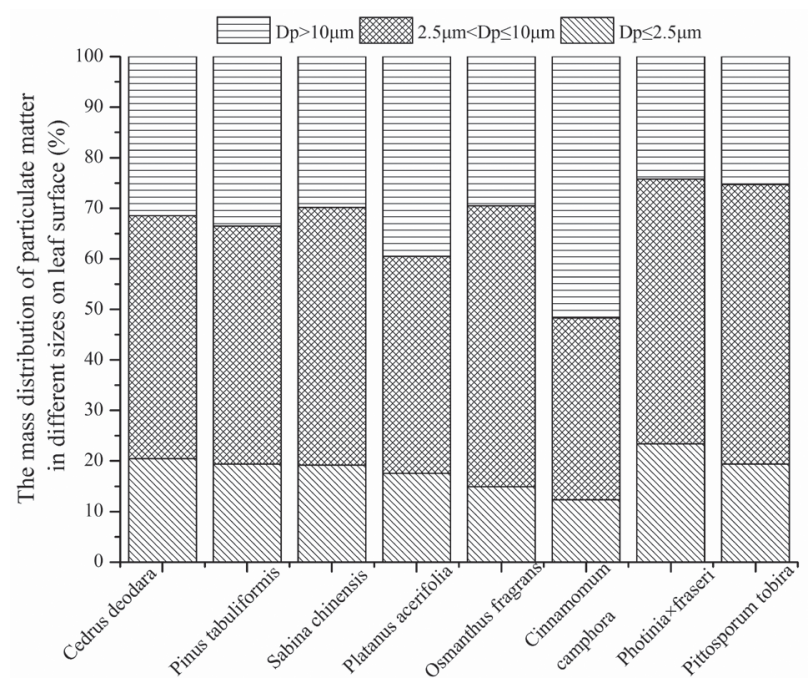

Fig. 3. The mass distribution of particulate matter in different sizes on leaf surface of the eight investigated tree species. contribution to the total mass of PM. The retention of $\mathrm{PM}_{2.5}$ is below $25 \%$, with the average ratio being $18.3 \%$, therefore the contribution to the total mass of particulate matter is small.

The results showed significant differences in the mass of PM deposition between different tree species (Fig. 3). The highest mass concentration of $\mathrm{Dp}>10 \mu \mathrm{m}$ was found on $C$. camphora leaves, which made a $51.67 \%$ contribution to the total PM (by wt) and was significantly higher when compared to the other 7 tree species. The large percentage of $\mathrm{PM}_{2.5-10}$ accounted for the majority of total PM (by wt) $(48.5 \%)$ among the 8 tree species, which was one of the most abundant size components. O. fragrans comprised $55.5 \%$ of the total PM (by wt), which indicated that $O$. fragrans leaves were more effective at accumulating $\mathrm{PM}_{2.5 \sim 10}$, but least effective in accumulating fine PM. Although representing a small percentage, this accumulation was significant, because $\mathrm{PM}_{2.5}$ is the most harmful to human health. The large PM accounted for the majority of the total PM (by $w t$ ), followed by $\mathrm{PM}_{10}$ and $\mathrm{PM}_{2.5}$. Similar conclusions were found in other studies [24, 27]. Popek et al. (2013) found that the percentages of fine, coarse, and large PM were $14 \%, 21 \%$, and $65 \%$, respectively [32]. The differences may be accounted for by the concentrations of each fraction in the air and by the leaf and structural characteristics of the studied tree species.

\section{The Quantitative Distribution of PM of Different Sizes on Leaf Surfaces Among Tree Species}

The number of particles deposited per $\mathrm{cm}^{2}$ leaf area varied greatly among species. Scanning electron microscopy (SEM) micrographs of the leaf surface structure of the 8 tree species are presented in Fig. 6. It can be clearly observed from SEM images that particles on the leaf are spherical in shape and combine to from aggregates, where most of the PMs were $<10 \mu \mathrm{m}$ and the quantity of adaxial particles was higher than that of abaxial. Wang et al. (2006) indicated that the abaxial surface capability was stronger than that of the adaxial surface capability [33], which is consistent with our research. 


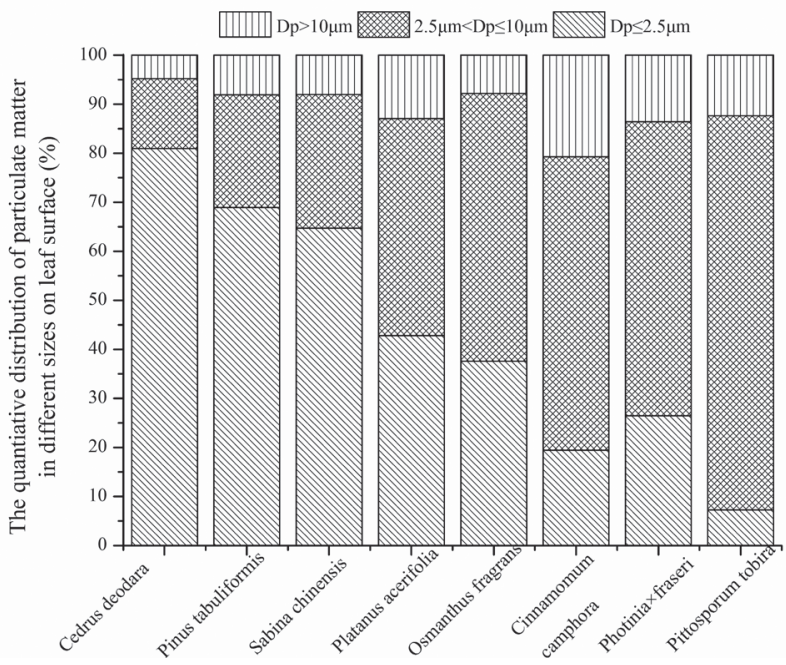

Fig. 4. The quantitative distribution of particulate matter in different sizes on leaf surface of the eight investigated tree species in Nanjing.

The PM density was recalculated into 3 size categories: $\mathrm{PM}_{>10}, \mathrm{PM}_{2.5 \sim 10}$, and $\mathrm{PM}_{2.5}$. Fig. 4 shows the different tree species' abilities in collecting different sizes of particles. Looking at the particulate size distribution (Fig. 4), the number of particles with diameters larger than $10 \mu \mathrm{m}$ was rare compared to $\mathrm{PM}_{2.5 \sim 10}$ and $\mathrm{PM}_{2.5}$, which is consistent with what Ottelé et al. (2010) [25] and Perini et al. (2017) found [10]. The results showed that $\mathrm{PM}_{2.5}$ accounted for approximately $94.5 \%$ of the total PM number per leaf unit area, while $\mathrm{PM}_{2.5 \sim 5}$ accounted for $21.5 \%$, and $\mathrm{Dp}>10$ only accounted for approximately $5.5 \%$. For tree species, C. deodara leaves had a higher number density of $\mathrm{PM}_{>10}$ and $\mathrm{PM}_{2.5 \sim 10}$ in all of the size fractions when compared to the other species, and P. tabuliformis leaves had a higher number density of $\mathrm{PM}_{2.5}$ when compared to the other species.

Song et al. (2015) found that particles less than $2.5 \mu \mathrm{m}$ accounted for $96 \%$ of the total number of particles on the leaf, which indicated that the number of fine particles was the major component of the total number of particles in Beijing, where $\mathrm{PM}_{2.5 \sim 10 \mu \mathrm{m}}$ accounted for $3.7 \%$ and particle sizes greater than $10 \mu \mathrm{m}$ only accounted for $0.14 \%$ [24]. The characteristics of the quality and number of the grain size distributions were diametrically opposite. The minimum percentage quantity of total particles was found in fine particles, which only account for $2.09 \%$. The percentage of $\mathrm{PM}_{2.5-10 \mathrm{\mu m}}$ accounted for $18.88 \%$, while particle sizes greater than $10 \mu \mathrm{m}(79 \%)$ were the biggest contributors. Similar to the conclusion of this study, Lu et al. (2008) found that $\mathrm{PM}_{10}$ distributions were the main part (50 60\%) of C. camphora and O. fragrans [34]. Tomasevic et al. indicated that the majority of particles observed on leaves belonged to a class of fine particles $(\mathrm{D}<2 \mu \mathrm{m})$ [35]. In conclusion, different sizes of particles among tree species indicated that among all grain size particles in the green tree species, the large particle size significantly contributes to the quality of the total

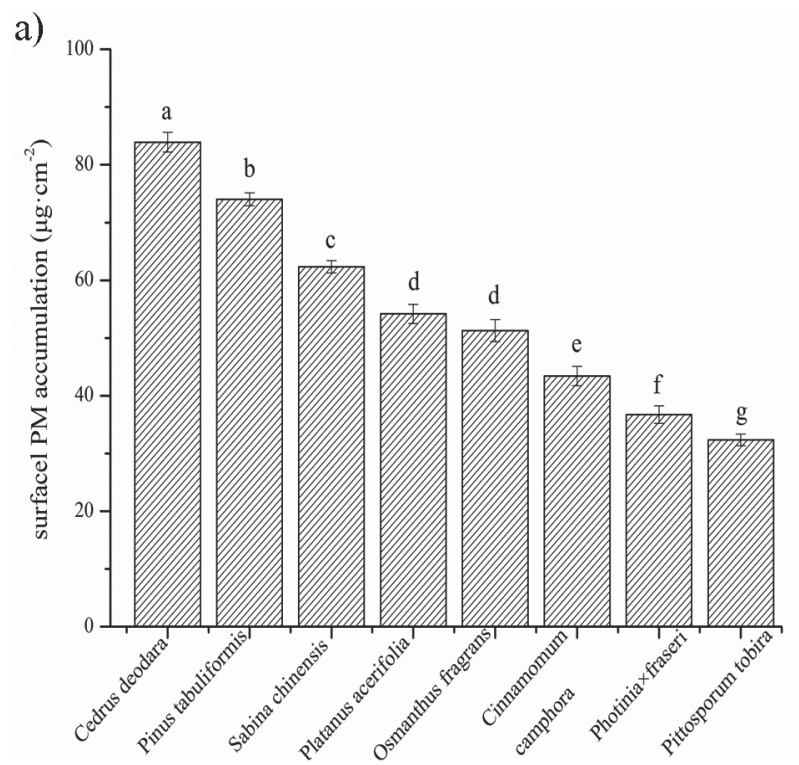

b)

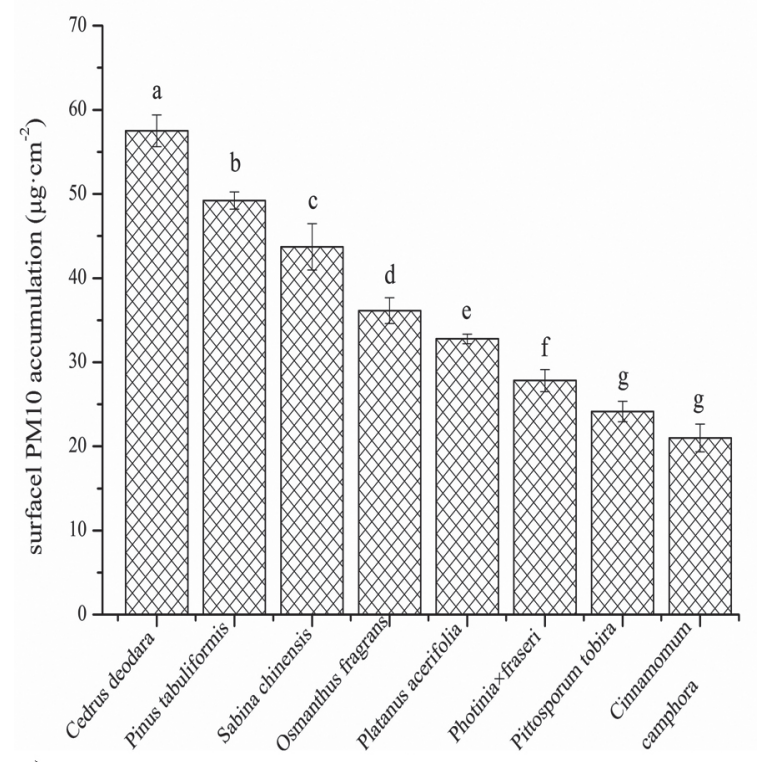

c)

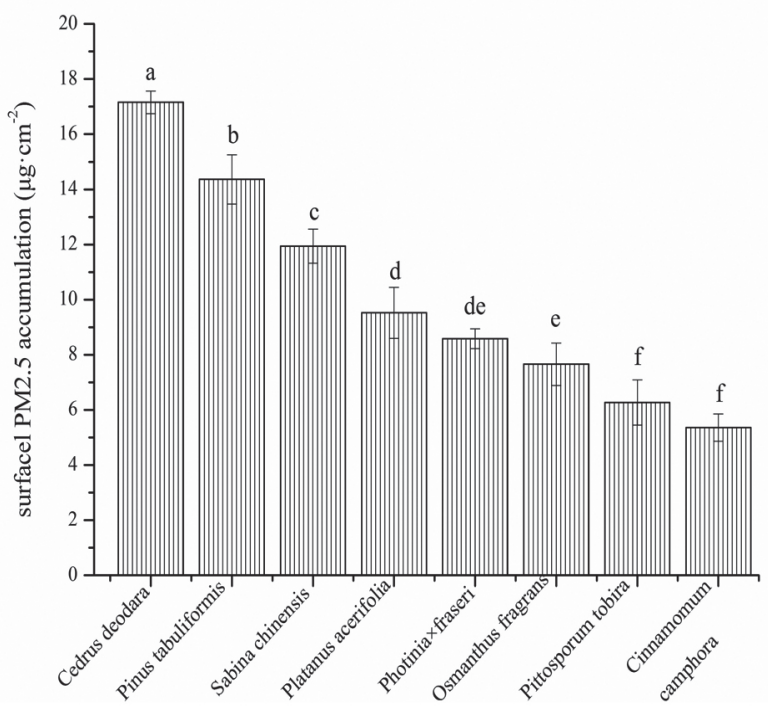

Fig. 5. The content of particulate matter on leaf surface of the eight investigated tree species on the basis of unit leaf area in Nanjing. a) total PM; b) $\mathrm{PM}_{10}$; c) $\mathrm{PM}_{2.5}$. 
particulate matter, and the fine particles with smaller particle sizes have a certain advantage in quantity.

The Mass of PM, $\mathrm{PM}_{10}$, and $\mathrm{PM}_{2.5}$ on Leaf Surfaces Among Tree Species

Similarly, there were significant differences in the quantity of particulate matter deposited on the 8 tree species $(P<0.05$; Figs 5a-c). The capacity of tree species to accumulate total PM decreased in the following order: C. deodara $>P$. tabuliformis $>S$. chinensis $>P$. acerifolia $>$ O. fragrans $>C$. camphora $>$ Photinia $\times$ fraseri $>$ P. tobira (Fig. 5a). The dust removed from the atmosphere by $C$. deodar had values of $83.92 \pm 1.72 \mu \mathrm{g} / \mathrm{cm}^{2}$, which was 2.59 times higher than the minimum of $32.35 \pm 1.02 \mu \mathrm{g} / \mathrm{cm}^{2}$ recorded for P. tobira. There is also a range of dust captured by the different tree species. Our results reveal that $C$. deodara, $P$. tabuliformis, and $S$. chinensis were the most efficient tree species for capturing PM. The mean amount of PM in coniferous species $\left(73.42 \mu \mathrm{g} / \mathrm{cm}^{2}\right)$ was 1.58 times higher than broadleaf species $\left(43.59 \mu \mathrm{g} / \mathrm{cm}^{2}\right)$, and the capacity of trees was higher than shrubs.

$\mathrm{PM}_{10}$ accumulation differences were also observed between species, as shown in Fig. 5b). For the 8 tree species, the average $\mathrm{PM}_{10}$ accumulation ranged from
$20.99 \pm 1.64 \mu \mathrm{g} / \mathrm{cm}^{2}$ to $57.51 \pm 1.87 \mu \mathrm{g} / \mathrm{cm}^{2}$. The $\mathrm{PM}_{10}$ removed from the atmosphere by $C$. deodar, which was 2.74 times higher than that of $P$. tobira and C. camphora. Cedrus deodara $\left(57.51 \pm 1.87 \mu \mathrm{g} / \mathrm{cm}^{2}\right)$, $P$. tabuliformis, and $S$. chinensis showed the highest $\mathrm{PM}_{10}$ accumulations on leaf surfaces. For 5 broadleaf species, the capacity of tree species to accumulate the $\mathrm{PM}_{10}$ were decreased in the following the order: O. fragrans $\left(36.14 \pm 1.53 \mu \mathrm{g} / \mathrm{cm}^{2}\right)>P$. acerifolia $\left(32.77 \pm 0.58 \mu \mathrm{g} / \mathrm{cm}^{2}\right)>$ P. fraseri $\left(27.82 \pm 1.30 \mu \mathrm{g} / \mathrm{cm}^{2}\right)$ $>$ P. tobira $\left(24.16 \pm 1.22 \mu \mathrm{g} / \mathrm{cm}^{2}\right)>C$. camphora $\left(20.99 \pm 1.64 \mu \mathrm{g} / \mathrm{cm}^{2}\right)$. The average large-surface $\mathrm{PM}_{10}$ accumulation of needle species is higher than broadleaf species. Different from the retention law of total particulate matter, the content of $\mathrm{PM}_{10}$ in 5 kinds of broadleaf species is more obvious, which indicates that the retention ability of conifer species for $\mathrm{PM}_{10}$ is stronger than that of broadleaf species, and the difference of $\mathrm{PM}_{10}$ between tree and shrub species is not significant. In conclusion, based on $\mathrm{PM}_{10}$ accumulation, the needle species ability is stronger than the broadleaf species ability. No significant differences were observed between trees and shrubs $(P>0.05)$, indicating that trees and shrubs do not significantly differ in $\mathrm{PM}_{10}$ accumulation.

For $\mathrm{PM}_{2.5}, \quad$ C. deodara $\left(32.77 \pm 0.41 \mu \mathrm{g} / \mathrm{cm}^{2}\right) \quad>$ P. tabuliformis $\left(14.36 \pm 0.89 \mu \mathrm{g} / \mathrm{cm}^{2}\right)>S$. chinensis
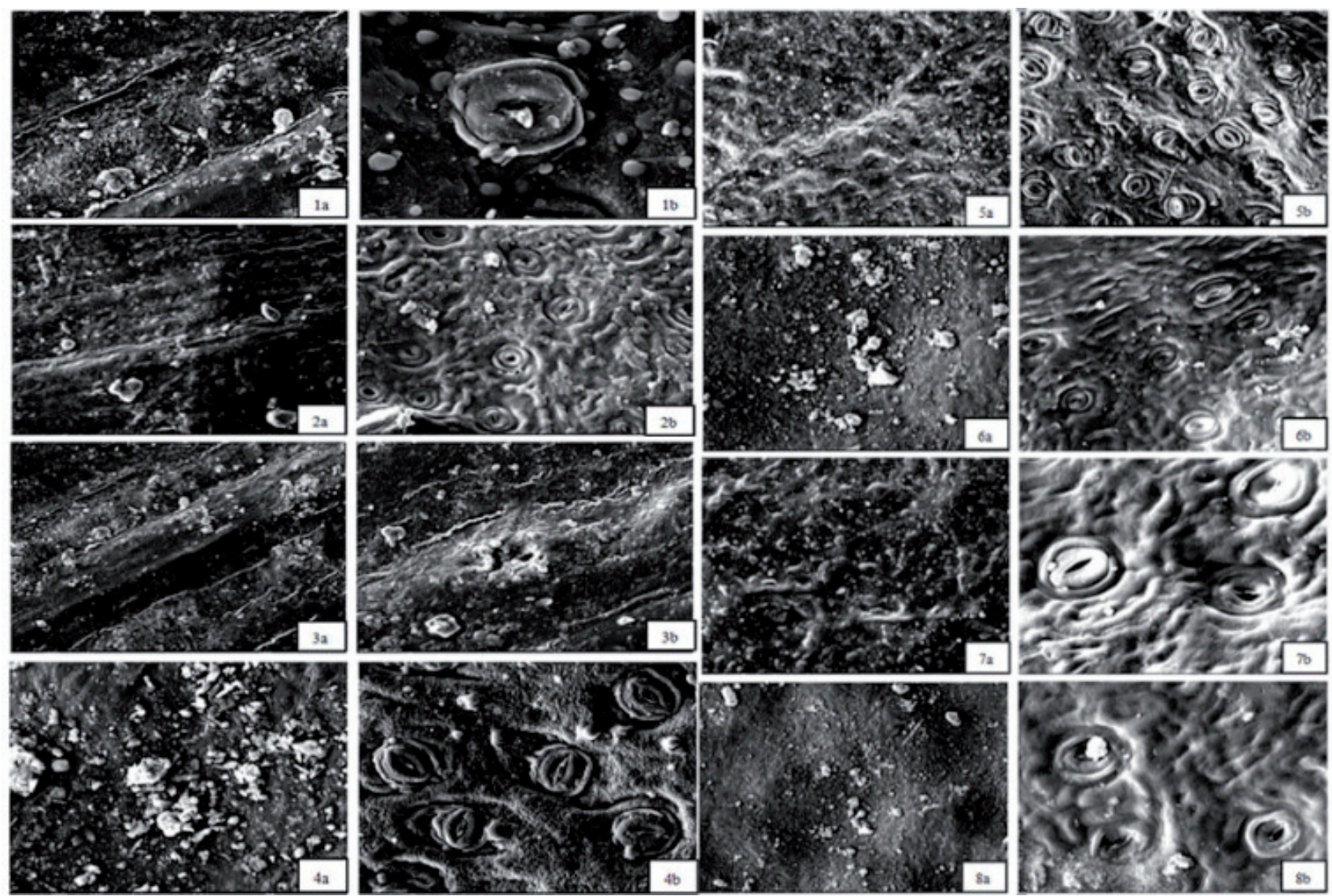

Fig. 6. Scanning elecrton micrographs of particulate matter morphology on leaf surface of the eight investigated tree species in Nanjing $(\times 2000)$ a) The adaxial leaf. b) The abaxial leaf. 1: C. deodara; P. tabuliformis; S. chinensis; P. acerifolia; O. fragrans; P. tobira; Photinia $\times$ fraseri; C. camphora. 
$\left(11.94 \pm 0.62 \mu \mathrm{g} / \mathrm{cm}^{2}\right)>$ P. acerifolia $\left(9.52 \pm 0.93 \mu \mathrm{g} / \mathrm{cm}^{2}\right)$ $>$ Photinia fraseri $\left(8.58 \pm 0.36 \mu \mathrm{g} / \mathrm{cm}^{2}\right)>O$. fragrans $\left(7.66 \pm 0.77 \mu \mathrm{g} / \mathrm{cm}^{2}\right)>$ P. tobira $\left(6.27 \pm 0.82 \mu \mathrm{g} / \mathrm{cm}^{2}\right)>C$. camphora $\left(5.36 \pm 0.29 \mu \mathrm{g} / \mathrm{cm}^{2}\right)$ (Fig. $5 \mathrm{c}$ ). From the point of view of needles and broadleaf trees, the $\mathrm{PM}_{2.5}$ capacity of the leaf area of broadleaf trees is less than coniferous trees. The leaf unit area of various coniferous species stranded in the $\mathrm{PM}_{25}$ content difference is also very significant. Combined with the above-mentioned data, for 8 kinds of common greening plant species' leaves in Nanjing, the unit area of $\mathrm{PM}_{2.5}$ of the total capacity is greater for coniferous tree species than broadleaf trees, and the leaf unit area of different broadleaf trees was stranded $\mathrm{PM}_{2.5}$ The difference was significantly smaller than that of coniferous trees. Beckett et al. indicated that this may be because most coniferous species have slender needles [36], rough leaf surfaces, complex stems, and annual leaf periods. Overall, the results indicate that differences in PM accumulation are probably the result of complex interactions between plant properties, climate, and other environmental factors. Additionally, the secretion of viscous matter can detain more particles, and the loss of particulate matter is small and not easily affected by rain or wind and other weather factors.

\section{Relationship between Morphological Characteristics and Mass of $\mathrm{PM}_{25}$ for 8 Tree Species}

As shown in Fig. 6, we can clearly see the irregular spheres, blocks, and polymers. For size distribution under $10 \mu \mathrm{m}$, the folds of the pores around the lamina and the stomata of the lower surface of the leaves are $\mathrm{PM}_{25}$ concentrated areas. According to statistics and analysis, the unit area of different tree species is $\mathrm{PM}_{2.5}$. The amount of the retention is positively correlated with stomatal density and pore size, and the fitting equation of stomatal density is $\mathrm{R}^{2}=0.837$ (Fig. 7), pore size is $\mathrm{R}^{2}=0.979$ (Fig. 8), and surface porosity is one of the important structures that affects the leaves of $\mathrm{PM}_{2.5}$. Burkhardt et al. (1995), through the wind tunnel experiment, observed that tiny particle sizes less than $0.5 \mu \mathrm{m}$ are mainly stranded near conifer porosity [37]. Schönherr et al. (2001) indicated that stomatal density and larger openings of leaves can retain more $\mathrm{PM}_{2.5}$ [38], which is consistent with our research. In addition, the arrangement of stomata might influence the ability of plants to retain particulates [39]. The plants with an orderly stomatal arrangement are stronger than those of disordered plants. More $\mathrm{PM}_{25}$ can be retained by the stomata of the plants (Figs 5-6). The residual amount of $\mathrm{PM}_{2.5}$ is consistent with stomatal density and pore size. This is because $\mathrm{PM}_{2.5}$ is composed of hygroscopic particles [37], and the more stomata on the surface of plant leaves, the more the transpiration effect, and the higher the humidity near the stomata. Therefore, the fine particulate matter on the leaf surface is deposited in the stomata and the retention content is higher.

Plant leaf villi can be secreted by the secretion of oil and juice to detain particulate pollutants in the atmosphere, so the shape, type, and density of the villi will have an impact on the $\mathrm{PM}_{25}$ retention abilities. Analysis shows that the unit area of different tree species has a positive correlation with the density of $\mathrm{PM}_{25}$ and the Pearson's correlation coefficient is 0.918 (Fig. 9). The results showed that the ability of plants with fine villi on the leaf surface to strand $\mathrm{PM}_{2.5}$ was more powerful.

The results show that the depth and width of the grooves also affect the effect of the plant leaves on $\mathrm{PM}_{25}$. The study found that the leaves of 8 kinds of green plants have different grooves on the surfaces of

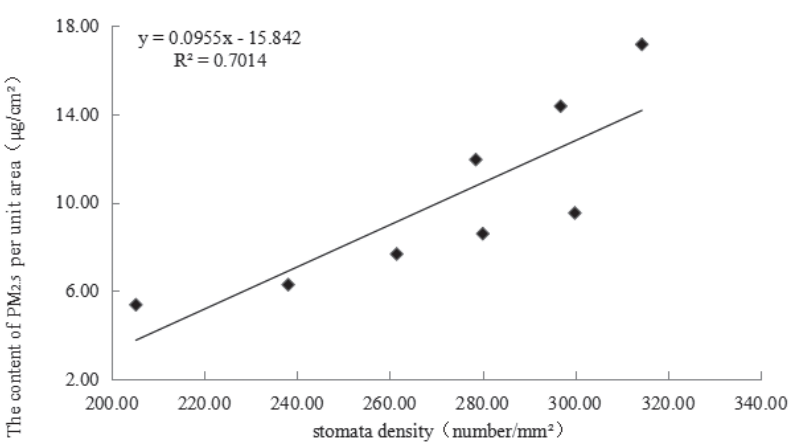

Fig. 7. Relationship between the content of $\mathrm{PM}_{2.5}$ per unite leaf area and stomata density of the eight investigated tree species.

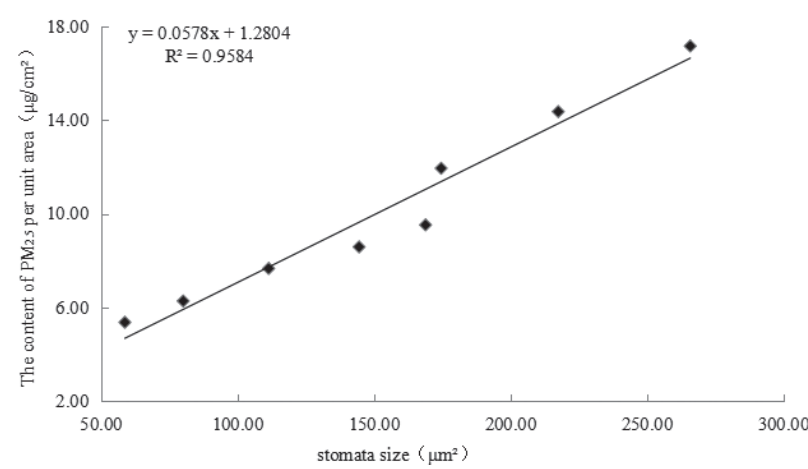

Fig. 8. Relationship between the content of $\mathrm{PM}_{25}$ per unite leaf area and stomata size of of the eight investigated tree species.

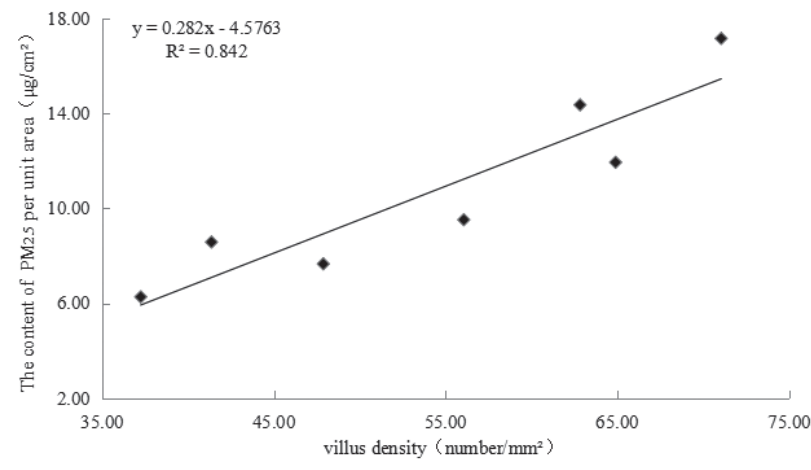

Fig. 9. Relationship between the content of $\mathrm{PM}_{2.5}$ per unite leaf area and villus density of the eight investigated tree species. 
their leaves (Fig. 6), except C. camphora, and it is more obvious in $O$. fragrans, $P$. acerifolia, and $C$. deodara. The deep grooves of C.deodara, $P$. tabuliformis, $P$. acerifolia, and $P$. fraseri are better than the shallow grooves of $S$. chinensis. O. fragrans, exhibiting a high stomata density, tend to retain more $\mathrm{PM}_{2.5}$. Xie indicated that a blade surface groove width of $5 \mu \mathrm{m}$ is the most powerful in $\mathrm{PM}_{2.5}$ retention [40]. The conclusion of the blade surface suitable groove width is consistent with the larger surface groove, which is not conducive to the retention of particles. However, Liang et al. (2016) found that no significantly positive correlations were found for leaf hairs and stomatal density, which indicated that a complex ecological environment may lead to different morphology characteristics [12].

\section{Conclusions}

Our study revealed the potential of urban tree species for particles deposited on leaf surfaces. The 8 tree species examined differed significantly in their ability to capture particulate matter from the presented results, which are as follows:

1) The highest recorded levels were found in traffic areas, and provided evidence that atmospheric loading may cause spatial variation in the amount of dust retained on trees. Significant differences were found between winter and the other 3 seasons.

2) Plants with large particles made the greatest contribution to the total mass of particulate matter, whereas $\mathrm{PM}_{2.5}$ made the greatest contribution to quantitative particulate matter.

3) The most efficient trees were $C$. atlantica, which effectively adsorbed significant quantities of total $\mathrm{PM}, \mathrm{PM}_{10}$, and $\mathrm{PM}_{2.5}$.

4) Important traits for $\mathrm{PM}_{2.5}$ accumulation were leaf properties such as villus density, stomata density, and size.

\section{Acknowledgements}

This study was financially supported by the Natural Science Major Projects in Jiangsu Province Colleges and Universities (No. 13KJA180002) and the Priority Academic Program Development of Jiangsu Higher Education Institutions (PAPD). The Doctorate Fellowship Foundation of Nanjing Forestry University also is gratefully acknowledged (2149025).

\section{Conflict of Interest}

The authors declare no conflict of interest.

\section{References}

1. OBERDÖRSTER G.Toxicology of ultrafine particles: in vivo studies. Philosophical Trans-actions of the Royal Society of London, A: Mathematical, Physical and Engineering Sciences. 358 (1775), 2719, 2010.

2. POPE C.A., HANSEN M.L., LONG R.W., NIELSEN K.R., EATOUGH N.L., WILSON W.E., EATOUGH D.J. Ambient particulate air pollution, heart rate variability, and blood markers of inflammation in a panel of elderly subjects. Environmental Health Perspectives. 112, 339, 2004.

3. FAIZ Y., THFAIL M., JAVED M.T., CHAUDHRT M.M., SIDDIQUE N. Road dust pollution of $\mathrm{Cd}, \mathrm{Cu}, \mathrm{Ni}, \mathrm{Pb}$ and Zn along Islamabad Expressway, Pakistan. Microchemical Journal. 92, 186, 2009.

4. KIM K.H., KABIR E., KABIR S. A review on the human health impact of airborne particulate matter. Environment International. 74, 136, 2015.

5. RAI P.K. Environmental magnetic studies of particulates with special reference to bio magnetic monitoring using roadside plant leaves. Atmospheric Environment. 72, 113, 2013.

6. HAN L., ZHOU W., LI W. Increasing impact of urban fine particles $\left(\mathrm{PM}_{2.5}\right)$ on areas surrounding Chinese cities. Scientific Reports. 5(7), 12467, 2015.

7. LI R., CUI L.L., LI J.L., ZHAO A., FU H.B., WU Y., ZHANG L.W., KONG LD., CHEN JM. Spatial and temporal variation of particulate matter and gaseous pollutants in China during 2014-2016. Atmospheric Environment. 161, 235, 2017.

8. ZHOU Z.X., SHAO T.Y., WANG P.C., GAO C., XU Y.Y., GUO E.X., XU L.H., YE Z.Q., PENG X.M., YU C.J. The spatial structure and the dust retention effects of green-land types in the workshop district of Wuhan Iron and Steel Company. Acta Ecologica Sinica. 22, 2036, 2010.

9. LIU L., GUAN D.S., PEART M.R.The morphological structure of leaves and the dust-retaining capacity of afforested plants in urban Guangzhou, South China. Environmental Science and Pollution Research. 19, 3440, 2012.

10. PETTIT T., IRGA P.J., ADOBO P., TORPY F.R. Do the plants in functional green walls contribute to their ability to filter particulate matter? Building and Environment. 2017. Building and Environment. 125, 299, 2017.

11. MO L., MA Z.Y., XU Y.S., SUN F.B., LUN X.X., LIU X.H., CHEN J.G., YU X.X. Assessing the capacity of plant species to accumulate particulate matter in Beijing, China, Plos one.1, 2015

12. LIANG D., MA C., WANG Y.Q., WANG Y.J., CHEN X.Z. Quantifying $\mathrm{PM}_{2.5}$ capture capability of greening trees based on leaf factors analyzing. Environment Science and Pollution research. 23, 21176, 2016.

13. PERINI K., OTTELÉ M., GIULINI S., MAGLIOCCO A., ROCCOTIELLO E. Quantification of fine dust position on different tree species in a vertical greening system. Ecological Engineering. 1000, 268, 2017.

14. HWANG H.J., YOOK S.J., AHN K.H. Experimental investigation of submicron and ultrafine soot particles by tree leaves. Atmospheric Environment. 45, 6987, 2011.

15. NGUYEN T., YU X., ZHANG Z., LIU M., LIU X. Relationship between types of urban forest and $\mathrm{PM}_{2.5}$ 
capture at three growth stages of leave. Journal of Environment Science-China. 27, 33-41, 2015.

16. BECKETT K.P., FREE-SMITH P.H., TAYLOR G. The capture of particulate pollution by trees at five contrasting UK urban sites. Arboricultural Journal. 24, 1, 2000.

17. FREER-SMITH P.H., BECKETT K.P, TAYLOR G. Deposition velocities to Sorbus aria, Acer campestre, Populus deltoides trichocarpa 'Beaupre', Piuns nigra and Cupressocyparis leylandii for coarse, fine and ultra-fine particles in the urban environment. Environment Pollution. 133, 157, 2005.

18. GRATANI L., CRECENTE M.F., VARONE L. Long-term monitoring of metal pollution by urban trees. Atmospheric Environment. 42, 8273, 2008.

19. LIU L., GUAN D.S., CHEN Y.D. Morphological structure of leaves and dust retaining capability of common street trees in Guangzhou Municipality. Acta Ecologica Sinica. 33 (8), 2604, 2013 [In Chinese].

20. NOWAK D.J., HIRABAYASHI S., BODINE A., GREENFIELD E. Tree and forest effects on air quality and human health in the United States. Environment Pollution. 193 (10), 119, 2014.

21. TERZAGHI E., WILD E., ZACCHELLO G., CERABOLINI B.E.L., JONES K.C., DIGUARDO A. 2013. Forest filter effect: role of leaves in capturing/releasing air particulate matter and its associated PAHs. Atmospheric Environment. 74 (8), 378, 2013.

22. WEBER F., KOWARIK I., SAUMEL I. Herbaceous plants as filters: immobilization of particulates along urban street corridors. Environment. Pollution. 186 (3), 234, 2014

23. TALLIS M., YATLOR G., SINNETT D., FREER-SMITH P. Estimating the removal of atmospheric particulate pollution by the urban tree canopy of London, under current and future environments. Landscape and Urban Planning. 103 (2), 129, 2011.

24. SONG Y.S., MAHER B.A., LI F., WANG X.K., SUN X., ZHANG H.X. Particulate matter deposited on leaf of five evergreen species in Beijing China: Source identification and size distribution. Atmospheric Environment. 105, 53, 2015.

25. OTTELÉ M., BOHEMEN H.D.V., FRAAIJ A.L.A. Quantifying the deposition of particulate matter on climber vegetation on living walls. Ecological Engineering. 36, 154, 2010.

26. HOFMAN J., STOKKAER I., SNAUWAERT L., SAMSON R. Spatial distribution assessment of particle matter in an urban street canyon using biomagetic leaf monitoring of tree crown deposited particles. 183, 123, 2013.

27. DZIERŻANOWKI K., POPEK R., GAWROŃSKA H., SEABØ A., GAWROŃSKA S.W. Deposition of particulate matter of different size fractions on leaf surfaces and in waxes of urban forest species. International Journal of Phytoremediation. 13, 1037, 2011.
28. QIU Y., GUANG D.S., SONG W.W., HUANG K.Y. Capture of heavy metals and sulfur by foliar dust in urban Huizhou, Guangdong Province, China, Chemosphere. 75, 447, 2009.

29. LIU L., GUAN D.S., PEART M.R. The morphological structure of leaves and the dust-retaining capability of afforested plants in urban Guangzhou, South China. Environment Science Pollution Research. 19, 3440, 2012.

30. SEABØ A., POPEK R., NAWROT B., HANSLIN H.M., GAWRONKSA H., GAWRONKI S.W. Plant species different in particulate matter accumulation on leaf surfaces. Science of the Total Environment. 427-428, 347, 2012.

31. PRZYBYSZ A., SEABØ A., HANSLIN H.M., GAWROŃSKI S.W. Accumulation of particulate matter and trace elements on vegetation as affected by pollution level, rainfall and the passage of time[J]. Science of the Total Environment. 481, 360, 2014.

32. POPEK R., GAWRONSKA H., WROCHNA M., GAWROŃSKI S.W., SEABØ A. Particulate matter on foliage of 13 woody species: Deposition on surfaces and phytostabilisation in waxes a 3 -year study. International Journal of Phytoremediation. 15, 245, 2013.

33. WANG L., GAO S.Y., LIU L.Y., HA S. Atmospheric particle-retaining capability of eleven graden tree species in Beijing. Chinese Journal of Applied Ecology. 17 (4), 597, 2006 [In Chinese].

34. LU S.G., ZHENG Y.W., BAI S.Q. A HRTEM/EDX approach to identification of the source of dust particles on urban tree leaves. Atmospheric Environment. 42 (26), 6431, 2008.

35. TOMAŚEVIĆ M., VUKMIROVIĆ Z., RAJŚIĆ S., TASIĆ M., STEVANOVIĆ B. Characterization of trace metal particles deposited on some deciduous tree leaves in an urban area. Chemosphere. 61, 753, 2005.

36. BRCKETT K.P., FREER-SMITH P.H., TAYLOR G. Particulate pollution capture by urban trees:Effect of species and wind speed.Global Change Biology. 6, 995, 2000.

37. BURKHARDT J., PETERS K., CROSSLEY A. The presence of structural surface waxes on coniferous needles affects the pattern of dry deposition of fine particles. Journal of Experimental Botany. 46 (288), 823, 1995.

38. SCHÖNHERR J., LUBER M. Cuticular penetration of potassium salts: Effects of humidity, anions and temperature. Plant and soil. 236, 117, 2001.

39. CHEN W., HE XY., ZHANG Y., SUN Y., WANG W.F., NING Z.H. Dust absorption effect of urban conifers in Northeast China. Chinese journal of applied ecology. 14 (12), 2113, 2003.

40. XIE B.Z., WANG H.X., YANG J., WANG Y.G., SHI H. Retention capability of $\mathrm{PM}_{25}$ and It's explanation by leaf surface Micro-structure of common board-leaved tree species in Beijing. Acta botanica boreali-Occidentalia sinica. 34 (12), 2432, 2014. 